\title{
Self-monitoring Intervention of Problem Behavior of Students with ADHD Learning in Regular Classroom in China
}

\author{
Cui Yin ${ }^{1}$, Yawen Xiao ${ }^{1}$, Wangqian $\mathrm{Fu}^{2}$
}

\author{
${ }^{1}$ Master Student, School of Education, Beijing Sport University, Beijing, 100084, China \\ ${ }^{2}$ Assistant Professor, School of Special Education, Beijing Normal University, Beijing, 100875, China \\ Correspondence: Dr. Wangqian Fu, Assistant Professor, School of Special Education, Beijing Normal University, \\ Beijing, 100875, China.
}

Received: October 8, 2021

Accepted: November 4, 2021

Online Published: November 7, 2021

doi:10.11114/ijce.v5i1.5401

URL: https://doi.org/10.11114/ijce.v5i1.5401

\begin{abstract}
The number of children with attention deficit hyperactivity disorder (ADHD) is increasing in China, whose inattention, disorganization, and impaired hyperactivity cause challenges for their study and teachers' teaching activities in classroom. The study applied self-monitoring intervention for two children with ADHD learning in a primary school to improve their problem behaviors. We found self-monitoring intervention was likely to reduce their off-task behaviors, even for students with ADHD and ASD. Practical implication of the intervention is discussed in the paper.
\end{abstract}

Keywords: inclusive education, learning in regular classroom, behavioral intervention, ADHD

\section{Introduction}

Attention deficit hyperactivity disorder (ADHD) is a neurodevelopmental disorder characterized by inattention, disorganization, and impaired hyperactivity (APA, 2013). The children with ADHD are characterized by inattention, hyperactivity and impulsivity, which most often arise in early to middle childhood, resulting impairment across multiple domains of daily life activities (Antshel \& Hier, 2014). Globally approximately $3.4 \%$ of school-aged children have this disorder (Polanczyk et al., 2015). In recent years, the number of children diagnosed with ADHD in China has been on rise. The overall prevalence in children was $5.7 \%$, with an aggregate prevalence of $7.5 \%$ in boys and $3.4 \%$ in girls (Tong et al., 2013). The increasing number of ADHD students poses a considerable challenge to the development of quality education in China.

Some of the specific behaviors exhibited by the children with ADHD are challenging for both peers and teachers on a daily basis. Existing research takes a variety of approaches to intervention for students with ADHD (Camargo et al., 2014; Walton and Ingersoll, 2013; Carter et al., 2010), and also demonstrates the importance of intervention for the improvement of problem behaviors in students with ADHD. Despite numerous studies explore the intervention strategies for children with ADHD, most are conducted in western countries with vigorous strategies, including school-base cognitive-behavioral intervention (Bloomquist et al., 1991), Computerized Progressive Attentional Training (Shalev et al., 2007), play-based intervention (Wilkes-Gillan et al., 2011; Reinie et al., 2012), emotion understanding (Hare et al., 2021), physical activity intervention (Benzing, 2020) and so on.

Students with special needs can use the same types of self-regulation procedures to improve their academic performance and interactions in social situations (Graham et al., 1992). The self-regulatory mechanisms that children use can be fostered and improved through instruction (Gheragh et al., 2014; Harris, 1982; Scardamalia \& Bereiter, 1985). This is especially important for students receiving special services. The problems that many students with special needs experience are related in part to problems in the self-regulation of organized strategic behaviors (cf. Harris, 1982; Licht, 1983). For students with ADHD, an important characteristic of behavior well is developing ability to understand and regulate their own behavior. The development of such skills is an even more formidable task (Harris et al., 2005).

ADHD is not included in the categories of disabilities in legal level in China, while whose problem behaviors, especially the off-task behaviors are challenging in the inclusive setting (Wang \& Xiao, 2019; West et al., 2006). Effective intervention for problem behaviors of students with ADHD is worthwhile to study in China. The present study 
aims to exploring the effect of self-monitoring intervention in reducing behavioral problems in primary students with ADHD. Besides, ADHD is a highly co-morbid condition, particularly with autism spectrum disorder (ASD) (National Institute for Health and Clinical Excellence, 2018). Studies show that between 30 and 50\% of individuals with ASD also show ADHD symptoms (particularly at pre-school age), and similarly, estimates suggest two-thirds of individuals with ADHD show features of ASD (Davis \& Kollins, 2012). We included a student with ASD with ADHD symptoms as well in our study. The research question addressed in the study is that is self-monitoring strategy effective to improve problem behaviors of students with ADHD?

\section{Method}

\subsection{Participants and Procedure}

The intervention program was invited by a primary school due to the challenge behaviors of students with ADHD nominated by the head teachers severely affecting the daily teaching activities in classroom. There were two students learning in an elementary school in Beijing, participated in the intervention study. Students A was a child with ADHD, and Students B was a child with ASD with ADHD symptoms. Both of them are 8 years old boys. Teachers reported that they had difficulty following directions, working cooperatively with others, and completing class assignments and homework. They further indicated that they had difficulty with self-control, especially specially student B often left seat in class. The school got the consent of intervention from students and their parents. We conducted on-site observations of students and interviews with teachers and parents to get the basic information of the students (e.g. gender, age, intelligence level, interests, etc.), the learning performance in classrooms (e.g. listen to teachers, sit silently, participate in the learning activities.

Besides, the Child Behavior Checklist developed by Achenbach (1991), the Chinese version translated by Su et al (1995) and Conners Teacher Rating Scale (Conners, 1997) were used to measure the students' problem behaviors. Analysis of the observation and interview data revealed that both students had behavioral problems such as inattentiveness and hyperactivity. Student A had some development of social skills, did not have behavior problems such as schizoid, depression, and compulsiveness, showed hyperactive tendencies, and was vulnerable to behavior problems and inattentive-passive behavior problems in school. Student B has obvious psychological behavioral problems, showing hyperactive tendencies and frequently showing problematic behaviors such as spinning and leaving his seat; he may have behavior problems, inattentiveness-passive and hyperactivity at school, while his social skills are maladapted, and with low achievement.

\subsection{Intervention Implementation}

An 18-session-long intervention with two students was carried out. Self-monitoring strategy was applied in the study. This type of self-observation employs metacognitive skills and trains students to continually reflect on their own behavior and attention levels (Vannest et al., 2010). Design record forms to record the number of times a student's problem behavior occurs and take the appropriate reinforcement, thus helping the student to reduce the number of times the problem behavior occurs.

After initial familiarization with the students, the intervention program was continuously adjusted based on class observations. Student B's waiting awareness and command execution ability were poorly developed, and there was a significant tendency to be hyperactive and to leave his seat more frequently. Therefore, the intervention was scheduled for a total of 18 sessions, with the first session using drawing to build a good relationship with the students; the last session was a review and summary. The rest of the 16 sessions were mainly for student problem behavior intervention by the self-monitoring strategy.

The intervention for Student A focused on self-confidence development and attention training, using self-monitoring tables and token method as an aid. Before the formal intervention, we first discussed Student A's "hyperactive behavior" with him, asked him to rate his classroom performance, and analyzed the reasons for his score. After discussion, Student A thought that his hyperactive behaviors included "having trouble sitting in class, tearing his clothes, shaking his hands and feet, being easily attracted to things unrelated to class, and being distracted." Next, tell Student A how to use the self-monitoring strategy, and ask him to record the above inattentive behaviors as soon as he notices them. The intervention with Student B focused on attention training and reducing out-of-seat behavior, using self-monitoring scales and using the token method as an aid.

\section{Results}

\subsection{The Behaviors Scores of Students with ADHD Before and after Intervention}

After intervention, according to the Conners Teacher Rating Scale, Student A's scores on the factors of character issues, hyperactivity, and inattention-passivity all decreased, indicating a reduction in the likelihood of conflict with others and hyperactivity. The factor scores of Student B's character problems, inattentive-passive, and the index of hyperactivity 
decreased compared to the pretest, indicating that the student's hyperactive and impulsive behaviors decreased, but remained above the normal range. It indicated that the student B may still have a tendency to be distracted and hyperactive. According to the Social Competence Factor Scores, both Student A and B improved their scores on the sub-dimension of activity, social and school situation factors compared to the pretest, indicating that they made progress in the intervention. Besides, student B's school situation score was still below the normal range, indicating that he still had difficulties in the academic area. (see Table 1)

Table 1. Comparison of student scores before and after intervention

\begin{tabular}{|c|c|c|c|c|c|c|c|c|c|c|c|c|c|c|c|}
\hline \multirow{6}{*}{$\begin{array}{l}\text { Conners } \\
\text { Teacher } \\
\text { Rating } \\
\text { Scale }\end{array}$} & & & & \multicolumn{3}{|c|}{$\begin{array}{c}\text { Factor I } \\
\text { Character issues }\end{array}$} & \multicolumn{3}{|c|}{$\begin{array}{c}\text { Factor II } \\
\text { Hyperactivity }\end{array}$} & \multicolumn{3}{|c|}{$\begin{array}{c}\text { Factor III } \\
\text { Inattentive-Passive }\end{array}$} & \multicolumn{3}{|c|}{$\begin{array}{l}\quad \text { Factor IV } \\
\text { Index of } \\
\text { Hyperactivity }\end{array}$} \\
\hline & & $\begin{array}{c}\text { Age } \\
\text { (years) }\end{array}$ & $\begin{array}{c}\text { Gende } \\
\mathrm{r}\end{array}$ & $\mathrm{X}$ & SD & $\begin{array}{c}\mathrm{X}+2 \mathrm{~S} \\
\mathrm{D}\end{array}$ & $\mathrm{X}$ & SD & $\begin{array}{c}\mathrm{X}+2 \mathrm{~S} \\
\mathrm{D}\end{array}$ & $\mathrm{X}$ & SD & $\begin{array}{c}\mathrm{X}+2 \mathrm{~S} \\
\mathrm{D}\end{array}$ & $\mathrm{X}$ & SD & $\begin{array}{c}\mathrm{X}+2 \mathrm{~S} \\
\mathrm{D}\end{array}$ \\
\hline & \multirow[b]{2}{*}{ A } & $\begin{array}{l}\text { Pretest } \\
\text { Score }\end{array}$ & Male & $\begin{array}{c}2.5 \\
0\end{array}$ & $\begin{array}{c}0.8 \\
7\end{array}$ & 4.23 & $\begin{array}{c}2.2 \\
9\end{array}$ & $\begin{array}{c}0.8 \\
8\end{array}$ & 4.05 & $\begin{array}{c}1.7 \\
5\end{array}$ & $\begin{array}{c}1.3 \\
0\end{array}$ & 4.35 & $\begin{array}{c}2.7 \\
0\end{array}$ & $\begin{array}{c}0.6 \\
4\end{array}$ & 3.98 \\
\hline & & $\begin{array}{l}\text { Posttes } \\
\text { t score }\end{array}$ & Male & $\begin{array}{c}1.3 \\
8\end{array}$ & $\begin{array}{c}0.9 \\
9\end{array}$ & 3.36 & $\begin{array}{c}1.7 \\
1\end{array}$ & $\begin{array}{c}0.7 \\
0\end{array}$ & 3.11 & $\begin{array}{c}1.3 \\
8\end{array}$ & $\begin{array}{c}1.3 \\
2\end{array}$ & 4.01 & $\begin{array}{c}1.8 \\
0\end{array}$ & $\begin{array}{c}1.1 \\
7\end{array}$ & 4.13 \\
\hline & \multirow[t]{2}{*}{ B } & $\begin{array}{l}\text { Pretest } \\
\text { Score }\end{array}$ & Male & $\begin{array}{c}2.0 \\
0\end{array}$ & $\begin{array}{c}1.3 \\
2\end{array}$ & 4.65 & $\begin{array}{c}2.8 \\
6\end{array}$ & $\begin{array}{c}0.3 \\
5\end{array}$ & 3.56 & $\begin{array}{c}2.2 \\
5\end{array}$ & $\begin{array}{c}1.3 \\
0\end{array}$ & 4.85 & $\begin{array}{c}2.8 \\
0\end{array}$ & $\begin{array}{c}0.6 \\
0\end{array}$ & 4.00 \\
\hline & & $\begin{array}{l}\text { Posttes } \\
\text { t score }\end{array}$ & Male & $\begin{array}{c}1.2 \\
5\end{array}$ & $\begin{array}{c}0.9 \\
7\end{array}$ & 3.19 & $\begin{array}{c}2.4 \\
3\end{array}$ & $\begin{array}{c}0.7 \\
3\end{array}$ & 3.89 & $\begin{array}{c}2.1 \\
3\end{array}$ & $\begin{array}{c}1.0 \\
5\end{array}$ & 4.23 & $\begin{array}{c}2.2 \\
0\end{array}$ & $\begin{array}{c}0.8 \\
7\end{array}$ & 3.94 \\
\hline \multirow{5}{*}{$\begin{array}{l}\text { Social } \\
\text { competenc } \\
\text { e factor } \\
\text { score }\end{array}$} & & \multicolumn{2}{|c|}{ Factor } & \multicolumn{4}{|c|}{ Activity } & \multicolumn{4}{|c|}{ Socialization } & \multicolumn{4}{|c|}{ School situation } \\
\hline & \multirow[t]{2}{*}{$\mathrm{A}$} & \multicolumn{2}{|c|}{ Pretest Score } & \multicolumn{4}{|c|}{8.5} & \multicolumn{4}{|c|}{7.33} & \multicolumn{4}{|c|}{1.00} \\
\hline & & \multicolumn{2}{|c|}{ Posttest score } & \multicolumn{4}{|c|}{10.5} & \multicolumn{4}{|c|}{9.33} & \multicolumn{4}{|c|}{2.25} \\
\hline & \multirow[t]{2}{*}{$\mathrm{B}$} & \multicolumn{2}{|c|}{ Pretest Score } & \multicolumn{4}{|c|}{7.5} & \multicolumn{4}{|c|}{4.67} & \multicolumn{4}{|c|}{1.00} \\
\hline & & \multicolumn{2}{|c|}{ Posttest score } & \multicolumn{4}{|c|}{11.00} & \multicolumn{4}{|c|}{5.67} & \multicolumn{4}{|c|}{1.25} \\
\hline
\end{tabular}

\subsection{The Improvement of Problem Behaviors of Students with ADHD}

Through the reward principle took the form of frequent reinforcement - gradual withdrawal, and eventually Student A's overall situation had improved. When summarizing with Student A in each session, he appeared to be looking forward to it. When reward was given to Student A, he appeared delighted. When some problem behaviors were found in the lesson, he did not show some emotional problems because of it. He will often tell the intervention teacher that "Teacher, I got it, I will pay attention afterwards; Teacher, I am especially happy that *** praised me today and I will behave well next." Through communication with the teacher and parents, they all said that Student A has become more open-minded than before and can get along with his classmates. The class teacher said that Student A had been moving around in class before, but now it was obvious that Student A was listening more carefully and sitting more regularly than before.

After receiving the intervention, the student improved the completeness of verbal expressions and the level of execution of instructions given by the teacher. The frequency of leaving the seat gradually decreased. Because the student's sense of rules had not yet been established, at the beginning of the course, Student B exhibited four times departures from his seat during the class. There were even situations where he left his seat and ran around the classroom in the middle of the intervention progress. After the intervention, Student B's awareness of rules gradually developed as well as the degree of following teacher's instructions increased, and the number of times he left his seat gradually decreased (see Figure 1). At the later stage of the intervention session, Student B had reached 0 occurrences of off-seat behavior. 


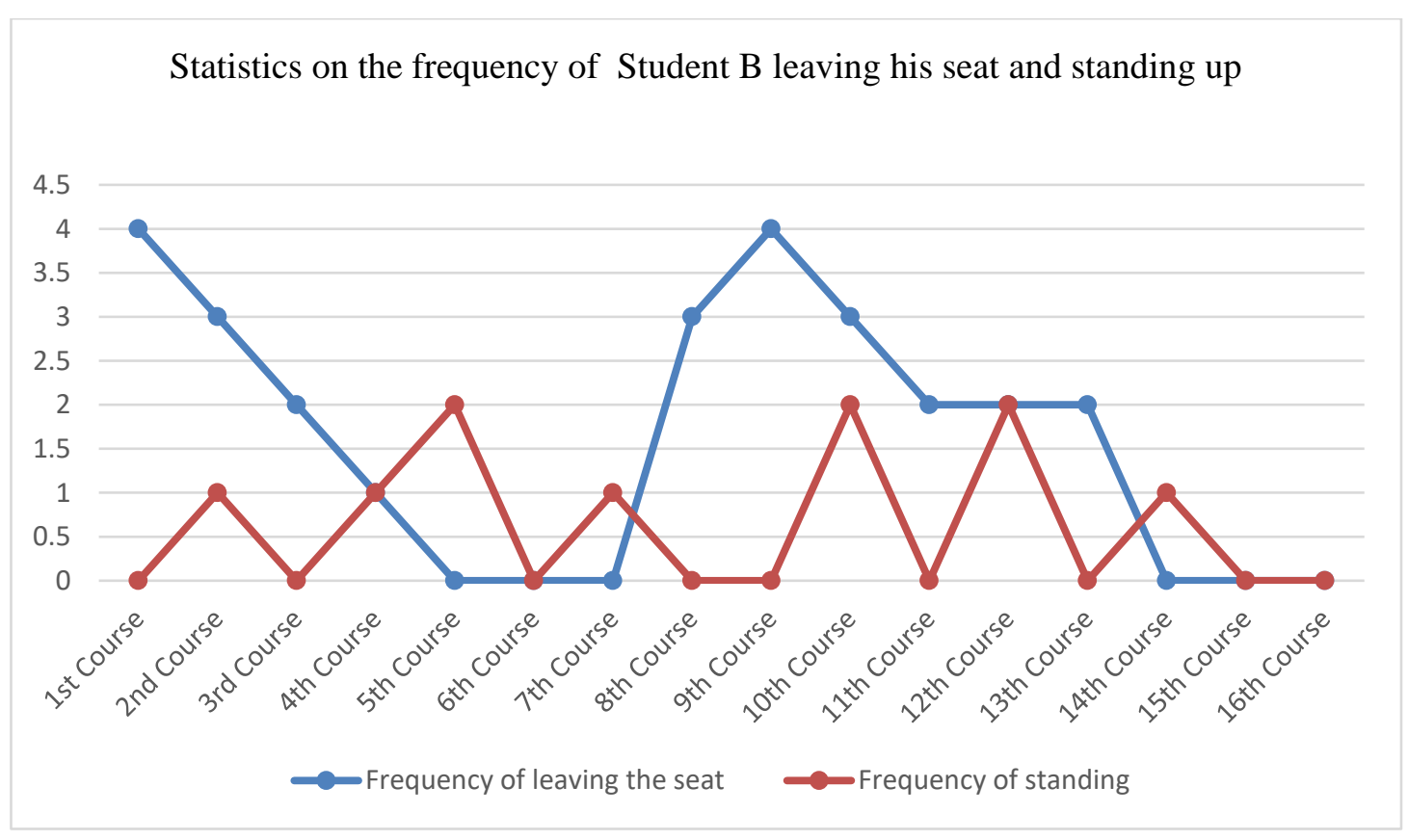

Figure 1. Statistics on the frequency of Student B leaving his seat and standing up

\section{Discussion}

The data of scales and on-site observation showed both students were improved after self-monitoring intervention on the on-task. It was clear that Student $\mathrm{A}^{\prime} \mathrm{s}$ classroom participation and concentration had improved. Later in the intervention, Student B's mother told us that Student B was now more sedentary than before, which was consistent with our observations of Student B in the classroom. It is evident that helping students recognize and record their emergent problem behaviors by adopting self-monitoring strategies, motivating and engaging students and reinforcing them, can have a greater complementary effect on their overall intervention effectiveness. It's consistent with the previous studies (Harris et al., 2005; Park, 2011; Feng, 2017; Wang, \& Xiao, 2019). Self-monitoring strategies enable subjects to clearly recognize and observe their own behavior, and to operate and record under clear instructions, helping them to make more targeted adjustments and management (Feng, 2017).

The development of self-regulation abilities can enhance the on-task and classroom performance of these students (DuPaul \& Stoner, 2002; Harris, 1982; Reid, 1996). By recording problem behaviors on their own, students take advantage of their age-specific needs for self-determination, self-management, and strong independence development, effectively stimulating their internal motivation (DuPaul \& Stoner, 2003; Feng, 2017). It assists students in working responsibly and independently (Burke, 1992), are often less intrusive than teacher-managed treatments (Fantuzzo et al., 1988), enhance students' control of their learning, and may be more effective than interventions managed primarily by the teacher (DuPaul \& Stoner, 2002). By making students more aware of their presence of hyperactive behaviors, it helps them to be able to effectively monitor their possible problem behaviors.

\section{Conclusions}

Based on the findings of the study, it is worth concluding that self-monitoring intervention have positive influence on improving problem behaviors of students with ADHD. The results of this study are significant for several reasons. First, the study demonstrated that self-monitoring interventions for students with ADHD can be implemented in Chinese education settings and the effect of it is recognized by teachers and parents as well. Furthermore, in the present study, self-monitoring was combined with external reinforcement and was effective. Much of the research involving self-monitoring among students with ADHD has included external reinforcement as a component (Harris et al, 2005); the need for, or additive effects of not external reinforcement should be considered in future research and intervention design.

In additions, there are some limitations in the study. Firstly, due to the relatively single object of this study, there may be cases of contingency. Following studies, can expand the scope of the study subjects to further support the relevant research theories. Secondly, the conduction of the study was convenient since it was invited by the primary school and they offered a lot of support in intervention implementation. Further studies can explore how to apply self-monitoring intervention in the general education classroom during common classroom tasks. 
Nowadays, inclusive education in China is in the transition stage from scale effect to quality improvement (Deng and Zhao, 2019). With the strong support of the state for the education of people with disabilities, the promotion of inclusive education, both in terms of social changes and financial subsidies, social support for families of children with special needs are improved. In addition to the national top-level design, there is an urgent need to address the issue of how to provide support for children learning in regular classroom at the micro-system level in order to optimize the impact of interventions. The implication is that when general teachers teaching students with ADHD, whose inattentive, disruptive, off-task, immature, and provocative behaviors affecting the classroom activated, self-monitoring intervention with external reinforcement can be applied. It's likely to reduce their off-task behaviors, even for students with ADHD and ASD.

\section{Funding}

This research is funded by the entrusted research program "evaluation and intervention training for students with ADHD".

\section{References}

Achenbach, T. M. (1991). The manual for the Child Behavior Checklist. Department of Psychiatry, 2, 4-18.

Antshel, K. M., \& Hier, B. O. (2014). Attention Deficit Hyperactivity Disorder (ADHD) in Children with Autism Spectrum Disorders. Springer: New York. https://doi.org/10.1007/978-1-4614-4788-7_53

Benzing. V. (2020). Exergaming-a physical activity intervention to benefit children with adhd? (phd academy award). British Journal of Sports Medicine, 54(15), 1-2. https://doi.org/10.1136/bjsports-2019-101920

Bloomquist, M. L., August, G. J., \& Ostrander, R. (1991). Effects of a school-based cognitive-behavioral intervention for ADHD children. Journal of Abnormal Child Psychology, 19(5), 591-605. https://doi.org/10.1007/BF00925822

Burke, J. C. (1992). Decreasing classroom behavior problems: Practical guidelines for teachers. San Diego: Singular

Camargo, S. P., Rispoli, M., Ganz, J., Hong, E. R., Davis, H., \& Mason, R. (2014). A review of the quality of behaviorally based intervention research to improve social interaction skills of children with ASD in inclusive settings. Journal of Autism and Developmental Disorders, 44, 2096-2116. https://doi.org/10.1007/s10803-014-2060-7

Carter, E. W., Sisco, L. G., Chung, Y. C., \& Stanton-Chapman, T. L. (2010). Peer interactions of students with intellectual disabilities and/or autism: a map of the intervention literature. Research \& Practice for Persons with Severe Disabilities, 35(3), 63-79. https://doi.org/10.2511/rpsd.35.3-4.63

Connors, C. K. (1997). Conners' Rating Scales-Revised Technical Manual. North Tonawanda, New York.

Davis, N. O., \& Kollins, S. H. (2012). Treatment for co-occurring attention deficit/hyperactivity disorder and autism spectrum disorder. Neurotherapeutics, 9(3), 518-530. https://doi.org/10.1007/s13311-012-0126-9

Deng, M., \& Zhao, H. (2019). Current Situation and Developmental Tendency of Inclusive Education in China in the New Era. Disability Research, (01), 12-18.

DuPaul, G. J., \& Stoner, G. (2002). Interventions for attention problems. In Fantuzzo, J. W., Polite, K., Cook, D. M., \& Quinn, G. (1988). An evaluation of the effectiveness of teacher-vs.-student-managed interventions with elementary school students. Psychology in the Schools, 25, 154-163. https://doi.org/10.1002/1520-6807(198804)25:2<154::AID-PITS2310250209>3.0.CO;2-M

Feng, Y. (2017). An Experimental Study of the Self-Monitoring-Dependent Improvement of Autistic Children's Attention to Academic Tasks and Academic Performance. Chinese Journal of Special Education, (09), 27-34.

Graham, S., Harris, K. R., \& Reid, R. (1992). Developing self-regulated learners. Focus on Exceptional Children, 24(6), 1-16. https://doi.org/10.17161/foec.v24i6.7539

Guilherme, Polanczyk, V., Giovanni, Salum, A., Luisa, \& Sugaya, S., et al. (2015). Annual research review: a meta-analysis of the worldwide prevalence of mental disorders in children and adolescents. Journal of Child Psychology \& Psychiatry. https://doi.org/10.1111/jcpp.12381

Gheragh, M. L., Khosravi, Z., \& Bani, J. (2014). The role of monitoring in reducing behavioral problems in 6-12 years old girls with adhd: a comparison between maternal monitoring and self monitoring.

Hare, M. M., Garcia, A. M., Hart, K. C., \& Graziano, P. A. (2021). Intervention response among preschoolers with ADHD: the role of emotion understanding. Journal of School Psychology, 84, 19-31. https://doi.org/10.1016/j.jsp.2020.11.001

Harris, K. R. (1982). Cognitive-behavior modification: Application with exceptional students. Focus on Exceptional 
Children, 15, 1-16. https://doi.org/10.17161/foec.v15i2.7449

Harris, K. R., Friedlander, B. D., Saddler, B., Frizzelle, R., \& Graham, S. (2005). Self-monitoring of attention versus self-monitoring of academic performance: effects among students with adhd in the general education classroom. Journal of Special Education, 39(3), 145-157. https://doi.org/10.1177/00224669050390030201

Johnny, L. M., \& Paige, E. C. (2014). Commonly studied comorbid psychopathologies among persons with autism spectrum disorder. Research in Developmental Disabilities, 35(5), 952-962. https://doi.org/10.1016/j.ridd.2014.02.012

Licht, B. (1983). Cognitive-motivational factors that contribute to the achievement of learning-disabled children. Journal of Learning Disabilities, 16, 483-490. https://doi.org/10.1177/002221948301600812

Park, S. (2011). Self-monitoring for students with ADHD: a look at self-monitoring strategies and their effects on improving attention and behavior for children with ADHD. Insights on Learning Disabilities.

Reinie, Cordier, Natalie, Munro, Sarah, \& Wilkes-Gillan, et al. (2012). The pragmatic language abilities of children with adhd following a play-based intervention involving peer-to-peer interactions. International Journal of Speech-language Pathology, 15(4). https://doi.org/10.3109/17549507.2012.713395

Reid, R. (1996). Research in self-monitoring with students with learning disabilities: The present, the prospects, the pitfalls. Journal of Learning Disabilities, 29, 317-331. https://doi.org/10.1177/002221949602900311

Scardamalia, M., \& Bereiter, C. (1985). Fostering the development of self-regulation in children's knowledge processing. In S. Chipman, J. Segal, \& R. Glaser (Eds.), Thinking and learning skills: Current research and open questions (Vol. 2, pp. 563-577). Hillsdale, NJ: Lawrence Erl-baum.

Shalev, L., Tsal, Y., \& Mevorach, C. (2007). Computerized progressive attentional training (cpat) program: effective direct intervention for children with ADHD. Child Neuropsychology, 13(4), 382-388. https://doi.org/10.1080/09297040600770787

Su, L. Y., Li, X. R., Luo, X. R., Yang, Z. W., \& Wan, G. B. (1995). Standardization of the Achenbach Child Behavior Scale in Hunan (boys 4 to 5, 6 to 11, and 12 to 16 years old). Journal of Clinical Psychosomatic Diseases, (02), 66-72+126.

Tong, L., Shi, H., \& Zang, J. (2013). Prevalence of ADHD in children of China: a systematic review and meta-analysis. Chinese Journal of Public Health, 29(09), 1279-1283.

Vannest, K. J., Davis, J. L., Davis, C. R., Mason, B. A., \& Burke, M. D. (2010). Effective intervention for behavior with a daily behavior report card: a meta-analysis. School Psychology Review, 39(4), 654-672.

https://doi.org/10.1080/02796015.2010.12087748

Walton, K. M., \& Ingersoll, B. R. (2013). Improving social skills in adolescents and adults with autism and severe to profound intellectual disability: A review of the literature. Journal of Autism and Developmental Disorders, 43, 594-615. https://doi.org/10.1007/s10803-012-1601-1

Wilkes-Gillan, S., Cordier, R., Bundy, A., Docking, K., \& Munro, N. (2011). A play-based intervention for children with ADHD: A pilot study. OT Australia 24th National Conference. https://doi.org/10.1111/j.1440-1630.2011.00928.x

Wang, L., \& Xiao, F. (2019). A Case Study of Inclusive Education Intervention of the Child with ADHD. Journal of Suihua University, 39(04), 11-16.

\section{Copyrights}

Copyright for this article is retained by the author(s), with first publication rights granted to the journal.

This is an open-access article distributed under the terms and conditions of the Creative Commons Attribution license which permits unrestricted use, distribution, and reproduction in any medium, provided the original work is properly cited. 